University of Nebraska - Lincoln

DigitalCommons@University of Nebraska - Lincoln

Faculty Publications from the Harold W. Manter Laboratory of Parasitology

4-1952

\title{
Helminths from the Round-Tailed Muskrat, Neofiber alleni nigrescens Howell, with Descriptions of Two New Species
}

Robert L. Rausch

Arctic Health Research Center, rausch@u.washington.edu

Follow this and additional works at: https://digitalcommons.unl.edu/parasitologyfacpubs

Part of the Parasitology Commons

Rausch, Robert L., "Helminths from the Round-Tailed Muskrat, Neofiber alleni nigrescens Howell, with Descriptions of Two New Species" (1952). Faculty Publications from the Harold W. Manter Laboratory of Parasitology. 560.

https://digitalcommons.unl.edu/parasitologyfacpubs/560

This Article is brought to you for free and open access by the Parasitology, Harold W. Manter Laboratory of at DigitalCommons@University of Nebraska - Lincoln. It has been accepted for inclusion in Faculty Publications from the Harold W. Manter Laboratory of Parasitology by an authorized administrator of DigitalCommons@University of Nebraska - Lincoln. 


\section{HELMINTHS FROM THE ROUND-TAILED MUSKRAT, NEOFIBER ALLENI NIGRESCENS HOWELL, WITH DESCRIPTIONS OF TWO NEW SPECIES}

\section{ROBERT RAUSCH ${ }^{1}$}

The helminths parasitic in the round-tailed muskrat, a microtine rodent of very restricted geographical range, have not been investigated. Two specimens of this mammal, collected in Putnam County, Florida, were included among a collection of microtine rodents made available to the writer by Mr. W. B. Quay, Museum of Zoology, University of Michigan. Appreciation is expressed here for the opportunity to examine this valuable material.

Both the animals were infected by helminths, of which four species were represented. One harbored two species of cestodes and one species of trematode in the intestinal tract; the other showed a heavy cysticercus infection of the liver. Two species, a trematode and a cestode, are described as new. The remaining two species constitute new host records.

Several hundred small trematodes of the genus Quinqueserialis Skvortsov, 1935, were found in the cecum of one of the rodents. These specimens clearly represent an undescribed species:

\section{Quinqueserialis floridensis n. sp.}

(Figs. 1-3)

Diagnosis: Body oval, slightly attenuated anteriorly, with concave ventral surface; 1.2 to 1.7 $\mathrm{mm}$. long by 700 to $900 \mu$ in greatest width. Cuticular spines not observed. Ventral surface with five rows of glands; mesal row has 16 glands; paramesal rows have 16 glands; lateral rows have 13 or 14 glands. Oral sucker from 140 to $165 \mu$ in diameter. Esophagus typical for genus. Sinuous intestinal crura pass mediad of vitellaria and testes, and terminate just below margins of latter. Excretory pore median, situated at level just posterior to ends of intestinal ceca. Lobed testes immediately posterior to vitellaria; testes measure 140 to $180 \mu$ in greatest length. Long axis of testes transverse, oblique, or longitudinal. Seminal vesicle well developed; convolutions numerous at posterior end of cirrus sac. Cirrus sac, 310 to $430 \mu$ long by about $75 \mu$ in greatest width, extends from genital pore near bifurcation of intestinal ceca posteriorly to point at level of most anterior loop of uterus. Cirrus provided with numerous conical spines. Coarsely lobed ovary intercecal, situated at same level as testes. Ovary size about half that of testes. Welldeveloped Mehlis' gland pre-ovarian. Uterus has seven, sometimes eight, transverse loops which extend laterally beyond intestinal ceca and vitellaria, nearly reaching body margins. Metraterm strongly developed, averaging half the length of cirrus sac. Vitellaria consist of two lateral groups of 12 to 15 follicles, compactly arranged. Vitellaria situated extracecally just anterior to testes, which they approximate in size, and almost wholly posterior to transverse uterine loops. Vitelline ducts strongly developed. Ovoid eggs from 14 to $16 \mu$ long by 8 to $10 \mu$ wide. Polar filament not observed.

Host: Neofiber alleni nigrescens Howell.

Habitat: Cecum of host.

Locality: Putnam County, Florida.

Type: A slide, No. 47587, containing whole mounts of paratype material, has been deposited in the Helminthological Collection of the U. S. National Museum.

Quinqueserialis floridensis, the smallest species of the genus, is readily differentiated from the three previously known species [Q. quinqueserialis (Barker and Laughlin, 1911); Q. hassalli (McIntosh and McIntosh, 1934); Q. wolgaensis

Received for publication, November 2, 1951.

1 Parasitologist, Animal-borne Disease Branch, Arctic Health Research Center, U. S. Public Health Service, F.S.A., Anchorage, Alaska. 
Skvortsov, 1935]. The three previously-known species are very similar in most details of their morphology, but differ essentially in number of ventral glands, egg size, and in other, more minor, details. They have two characters in common which set them off clearly from the species described herein: (1) the vitellaria are arranged in longitudinal, mostly extracecal, lateral rows; $(2)$ the uterine convolutions do not pass to any marked extent lateral to the intestinal ceca.

$Q$. floridensis can be differentiated most readily on the basis of these characters, since in this species the vitellaria consist of two lateral bodies largely posterior to the uterine coils. In this species, moreover, the uterine coils are peculiar in that they extend laterally well beyond the lateral margins of the intestinal ceca and vitellaria and, in fact, in some specimens practically are in contact with the lateral bodymargins of the worm. $Q$. floridensis is differentiated further on the basis of ventral gland numbers, and on egg size.

The trematodes of the genus Quinqueserialis are typically parasitic in the cecum of microtine rodents. $Q$. quinqueserialis is commonly observed in the muskrat; $Q$. hassalli occurs, usually in relatively small numbers, in the cecum of Microtus spp. (vide McIntosh and McIntosh, 1934; Harwood, 1939; Rausch and Tiner, 1949; Kuns and Rausch, 1950). Q. wolgaensis was also collected from the cecum of a vole, Arvicola terrestris (L.) by Skvortsov (1935). Whether Q. floridensis n. sp. occurs in other microtine hosts remains to be seen.

A single cestode of the genus Cittotaenia Riehm was removed from the small intestine of one of the rodents. Although gravid and late pre-gravid segments were absent, the strobila measured $65 \mathrm{~mm}$. in length, and $3 \mathrm{~mm}$. in greatest width. In the absence of completely developed eggs, one often cannot assign cestodes of this group with certainty to a given species. However, a study of the morphology of this worm fails to disclose any character which is incompatible with its assignment to the species $C$. praecoquis Stiles, 1895.

C. megasacca was described by Smith (1951) from a pocket gopher (Thomomys) from Wyoming. The comparison of the Neofiber cestode with specimens of $C$. megasacca, collected by the writer from a pocket gopher, Thomomys talpoides tenellus Goldman, from northern Wyoming, has disclosed clear-cut differences. The occurrence of $C$. praecoquis as a parasite in Neofiber constitutes a new host record, and considerably increases the known geographical range of this helminth.

Found along with the specimen of $C$. praecoquis, in both the stomach and duodenum of the host, were several specimens of a cestode of the genus Paranoplocephala Luehe. Since these cestodes differ significantly from other members of the genus, they are described herewith as a new species. The following description is based mainly on two entire specimens:

\section{Paranoplocephala neofibrinus n. sp.}

(Figs. 5-6)

Diagnosis: Strobila length 55 to $56 \mathrm{~mm}$; greatest width, attained in region of early gravid segments (in last one-fourth of strobila), $5 \mathrm{~mm}$. Strobila, consisting of 180 to 190 segments, strongly attenuated anteriorly. Segments, in mature region, much wider than long (ratio of length to width about $1: 10$ ) ; length becomes greater in gravid segments, of which the terminal ones have a ratio of about $1: 3$. Scolex, distinctly set off from neck, has diameter of 600 to $750 \mu$. Suckers round; 250 to $290 \mu$ in diameter. Excretory canals not enlarged. Genital pores unilateral, dextral, situated near middle of segmental margin. Genital ducts dorsal to longitudinal excretory canals. Subspherical testes, about 50 to $60 \mu$ in diameter in mature segments, extend 
Rausch in Journal of Parasitology (April 1952) v. 38, no. 2.

Copyright 1952, American Society of Parasitologists. Used by permission..

RAUSCH-NEW HELMINTHS FROM MUSKRAT
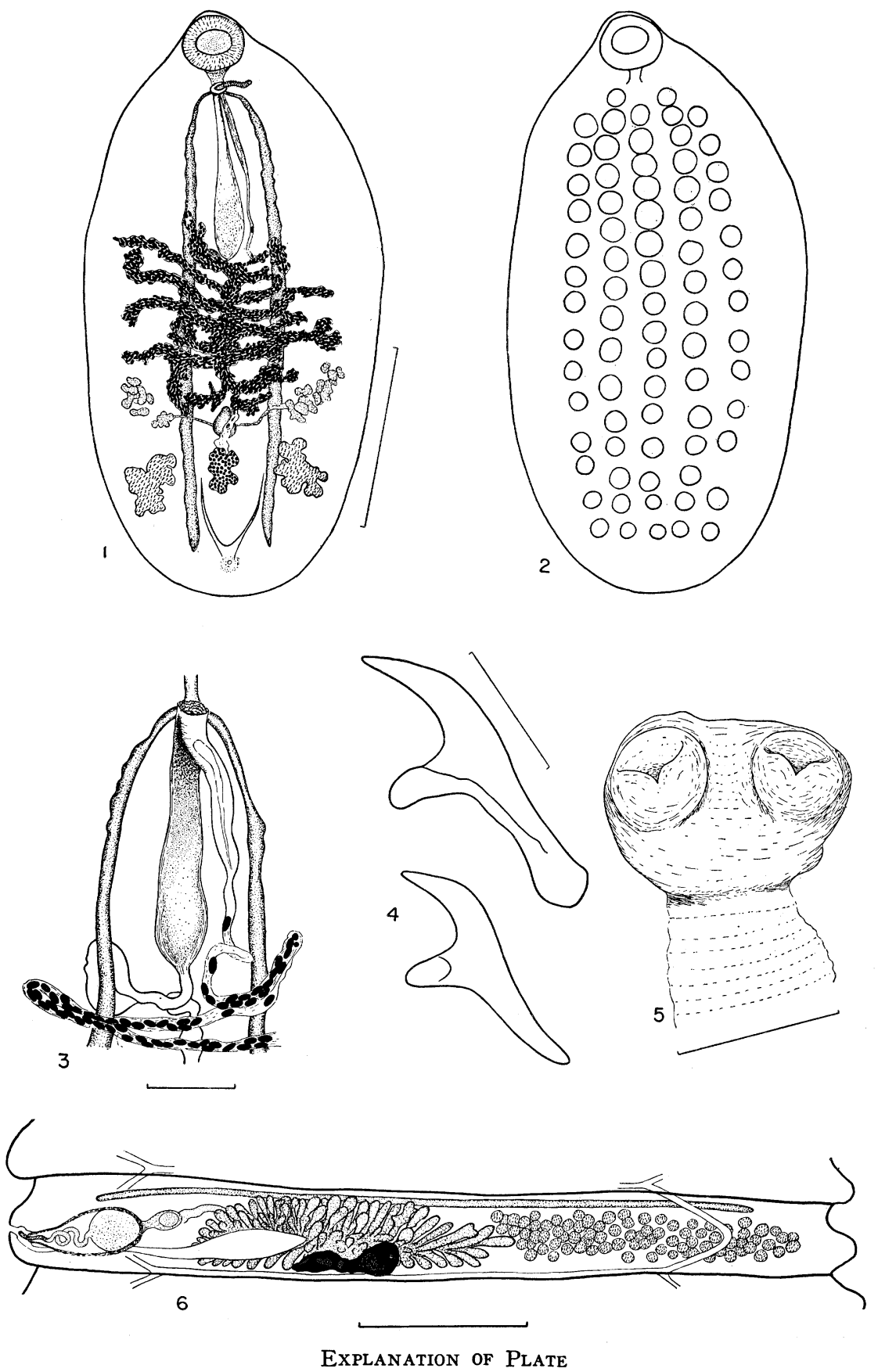

(All figures drawn with aid of projector.)

Fig. 1. Quinqueserialis floridensis n. sp.; ventral view, ventral glands omitted. Scale has a value of $500 \mu$.

FIG. 2. Q. floridensis n. sp.; ventral view, showing distribution of glands.

FIG. 3. $Q$. floridensis n. sp.; details of terminal portions of genital ducts. Scale has a value of $100 \mu$.

Fig. 4. Rostellar hooks of Taenia ?lyncis Skinker, 1935. Scale has a value of $100 \mu$.

FIG. 5. Paranoplocephala neofibrinus n. sp.; scolex. Scale has a value of $500 \mu$.

Fig. 6. $P$. neofibrinus n. sp.; mature segment, ventral view. Scale has a value of $500 \mu$. 
from aporal edge of ovary to well beyond aporal longitudinal excretory canals. Testes, extending through nearly entire length of segment, number about 100 ; exact count not possible because of their overlapping and close apposition. Ovoid to pyriform cirrus sac prominent, extending across longitudinal excretory canals on poral side; cirrus sac measures from 360 to $380 \mu$ in length by 130 to $136 \mu$ in greatest width in mature segments. Heavily-spined cirrus looped in distal portion of cirrus sac. Large internal seminal vesicle occupies about one-half of cirrus sac. External seminal vesicle well developed. Vagina opens postero-ventral to cirrus sac opening; it may extend somewhat posterior to latter in course of passage medially toward ovary. Seminal receptacle very large in late mature segments, extending aporally beyond middle of ovary. Vitelline gland elongate, variable in shape, situated at base of ovary near middle. Highly-lobed ovary situated almost entirely in poral half of segment, extending in mature segments through entire segmental length. Uterus tubular, extending laterally beyond longitudinal excretory canals; uterine sacculations gradually enlarge, filling entire gravid segment. Eggs measure 38 to $43 \mu$ long by 32 to $43 \mu$ wide (av. 41 by $37 \mu$ ). Pyriform apparatus well developed.

Host: Neofiber alleni nigrescens Howell.

Habitat: Small intestine.

Locality: Putnam County, Florida.

Type: A slide, No. 47588, bearing an entire specimen has been deposited in the Helminthological Collection of the U. S. National Museum.

Paranoplocephala neofibrinus is differentiated from related species primarily on the basis of egg-size and cirrus sac-size and more detailed characteristics. Referring to the work of Rausch and Schiller (1949a) in their review of North American species of Paranoplocephala in Microtus, $P$. neofibrinus is most closely related to $P$. variabilis (Douthitt, 1915). $P$. variabilis has an aspinose cirrus, a smaller cirrus sac, and much smaller eggs ( 26 to $33 \mu$ long by 20 to $26 \mu$ wide). Grossly the two species are similar, except for the relatively much larger scolex of $P$. neofibrinus. Both also occur in the same habitat-the duodenum of the host.

After the paper by Rausch and Schiller had been published, the description of P. kirbyi Voge, 1948, appeared in a journal long delayed beyond scheduled date of publication. In connection with other work, the writer borrowed the type specimen of $P$. kirbyi from the U. S. National Museum, and Dr. Voge very kindly provided additional specimens from the type host, Microtus californicus. A careful study of this material revealed that the specimens upon which $P$. kirbyi is based were erroneously assigned to genus, and they actually represent specimens of Andrya macrocephala Douthitt, 1915. Such an error might readily enough occur if one misinterpreted the details of uterine formation, since this character, the most important for generic differentiation, often is obscure. That $A$. macrocephala is a very variable species has been shown by Rausch and Schiller (1949b). The morphology of the specimens upon which " $P$. kirbyi" is based will be discussed further, more appropriately, in another publication (Rausch, 1952).

Among Eurasian species of Paranoplocephala, P. omphalodes (Hermann, 1783) is the only species, on the basis of published descriptions, which $P$. neofibrinus might resemble. However, through the study of comparative material, and because of discrepancies in the published descriptions, $P$. neofibrinus is considered clearly distinct from $P$. omphalodes. Although reported by Harkema (1946) from the cotton rat (Sigmodon) in North Carolina, P. omphalodes is not known to occur in the United States. The original identification of this cestode was erroneous (cf. Harkema and Kartman, 1948; p. 185 : Andrya microti Hanson). This earlier published record was unfortunately not clarified by Harkema and Kartman in their later publication on the parasites of the cotton rat. P. omphalodes was recorded from arctic Alaska by Rausch (1951) ; the occurrence of this species in North America will be discussed in another publication (Rausch, 1952). 
One of the round-tailed muskrats examined in connection with this study showed a heavy liver infection by larval cestodes belonging to the genus Taenia L. Sixteen cysticerci were observed, localized on both the dorsal and ventral surfaces of the organ. The cysts measured, on the hepatic surface, 3 to $4 \mathrm{~mm}$. in diameter. The cysticerci possessed from 40 to 44 rostellar hooks (Fig. 4). The large hooks measured from 220 to $244 \mu$ in length, and the small hooks measured from 172 to $187 \mu$ in length.

In the absence of adult cestodes for detailed morphological study, specific identification of these cysticerci can hardly be made. A review of available information on hook details of cestodes of the genus Taenia indicates that the hooks of these cysticerci closely resemble those of T. lyncis Skinker, 1935. Harkema and Kartman (1948) tentatively identified as T. lyncis a cysticercus from the liver of a cotton rat. Skinker (1935) recorded deer and a white-footed mouse (Peromyscus) as possible intermediate hosts of this cestode, but considered controlled feeding experiments necessary to establish with certainty the identity of such larvae. Joyeux (1945) also figured the hooks of Taenia sp. from Felis macrura, of Brazil. These hooks also closely resemble those of $T$. lyncis. The study of adult cestodes from Florida carnivores will be necessary to establish whether $C$. lyncis is present in that region.

\section{SUMMARY}

Two specimens of round-tailed muskrat, Neofiber alleni nigrescens Howell, were examined for helminth parasites. Four species, a trematode and three cestodes, were collected. Two of these, Quinqueserialis floridensis and Paranoplocephala neofibrinus, are described as new. Cittotaenia praecoquis Stiles, 1895, is recorded from this host, and larval cestodes are tentatively identified as Taenia lyncis Skinker, 1935.

\section{REFERENCES}

Harkema, R. 1946 The metazoa parasitic in cotton rats of Wake County. (N. C.) Abst. rept. 43rd Ann. Mtg. N. C. Acad. Sci. in J. Elisha Mitchell Sci. Soc. 62: 142-143.

AND Kartman, L. 1948 Observations on the helminths and ectoparasites of the cotton rat, Sigmodon hispidus Say and Ord, in Georgia and North Carolina. J. Elisha Mitchell Sci. Soc. 64: 183-191.

Harwoon, P. D. 1939 Notes on Tennessee Helminths. IV. North American trematodes of the sub-family Notocotylinae. J. Tenn. Acad. Sci. 14: 421-437.

Joyeux, CH. 1945 Cestodes du Brésil II. Arkiv for Zool. 37B : 1-5.

Kuns, M. L. AND RaUsch, R. 1950 An ecological study of helminths of some Wyoming voles (Microtus spp.) with a description of a new species of Nematospiroides (Heligmosomidae: Nematoda). Zoologica, New York Zool. Soc., 35: 181-188.

McIntosh, A. ANd McIntosh, G. E. 1934 A new trematode, Notocotylus hassalli, n. sp. (Notocotylidae), from a meadow mouse. Proc. Helm. Soc. Wash. 1: 36-37.

Rausch, R. 1951 Biotic interrelationships of helminth parasitism. Pub. Health Repts. 66: 928-934.

1952 Studies on the helminth fauna of Alaska. XI. Helminth parasites of microtine rodents-taxonomic considerations. (In manuscript).

and Schiller, E. L. 1949a Some observations on cestodes of the genus Paranoplocephala Luehe, parasitic in North American voles (Microtus spp.). Proc. Helm. Soc. Wash. 16: 23-31.

$\rightarrow$ AND Schiller, E. L. 1949b A critical study of North American cestodes of the genus Andrya with special reference to $A$. macrocephala Douthitt, 1915. (Cestoda: Anoplocephalidae). J. Parasit. 35: 306-313.

$\rightarrow-$ AND Tiner, J. D. 1949 Studies on the parasitic helminths of the North Central States. II. Helminths of voles (Microtus spp.) Preliminary report. Amer. Midl. Nat. 41: 665-694.

Skinker, M. S. 1935 Two new species of tapeworms from carnivores and a redescription of Taenia laticollis Rudolphi, $1819 . \quad$ Proc. U. S. Nat. Mus. 83: 211-220. 
Rausch in Journal of Parasitology (April 1952) v. 38, no. 2.

Copyright 1952, American Society of Parasitologists. Used by permission..

156

THE JOURNAL OF PARASITOLOGY

Skvortsov, A. A. $1935 \mathrm{~K}$ izuchenniu gel'mintofauny vodianykh krys Arvicola terrestris (L.). Vestnik. Mikrobiol. Epidemiol. i Parazitol. 13: 317-326.

$\rightarrow$ Sмгтн, C. F. 1951 Two anoplocephalid cestodes, Cittotaenia praecoquis Stiles and Cittotaenia megasacca n. sp. from the western pocket gopher, Thomomys talpoides, of Wyoming. J. Parasit. 37: 312-316.

$\rightarrow$ Voge, M. 1948 A new anoplocephalid cestode, Paranoplocephala kirbyi, from Microtus californicus californicus. Trans. Amer. Micr. Soc. 67: 299-303. 